\title{
Morbidity of Open Saphenous Vein Harvesting after Preoperative Ultrasonic Mapping
}

\author{
Susumu Isoda ${ }^{*}$, Tamizo Kimura², Katsunori Tanaka², Kenji Nishimura², \\ Nozomu Yamanaka ${ }^{2}$, Shin-ichi Taguchi' ${ }^{2}$, Keiji Uchida ${ }^{1}$, Norihisa Karube ${ }^{1}$, \\ Kiyotaka Imoto ${ }^{1}$ \\ ${ }^{1}$ Department of Cardiovascular Surgery, Yokohama City University Medical Center, Yokohama, Japan \\ ${ }^{2}$ Department of Cardiovascular Surgery, National Defense Medical College, Tokorozawa, Japan \\ Email: ${ }^{\text {isoda@yokohama-cu.ac.jp }}$
}

Received 2 February 2015; accepted 21 February 2015; published 28 February 2015

Copyright (C) 2015 by authors and Scientific Research Publishing Inc.

This work is licensed under the Creative Commons Attribution International License (CC BY). http://creativecommons.org/licenses/by/4.0/

(c) (7) Open Access

\section{Abstract}

Preoperative echography of a saphenous vein graft (SVG) was studied. In 58 cases of consecutive coronary artery bypass grafting, 31 patients underwent SVG echography. Preoperative assessment revealed vein caliber, branching, or varicose saphenous veins. The location of the saphenous vein was marked. Saphenous veins were harvested by the open harvest technique, and the caliber of the veins and the availability of the anastomosis device were recorded. Postoperative morbidity was recorded. Preoperative findings revealed that four (6.5\%) of 62 femoral saphenous veins were estimated as "not graftable" because of being a varicose vein or having a small caliber. Seven of 32 lower saphenous veins were estimated as "not graftable". The mean discrepancy of the caliber was $0.6 \mathrm{~mm}$ undersized with preoperative estimation. During harvesting, one of 31 patients had a wrong marking. We were able to use all harvested veins. The morbidity of saphenous harvesting was observed in two $(6.5 \%)$ of 31 patients. One patient whose marking was wrong had minor skin necrosis. Another patient experienced a hematoma because of the excess effect of warfarin. Preoperative ultrasonic mapping of the saphenous vein reduced useless harvesting, provided information concerning anastomosis device availability, and seemed to reduce morbidity because dissection can be minimal.

\section{Keywords}

Saphenous Vein, Ultrasonic Mapping, Coronary Artery Bypass Grafting

\footnotetext{
${ }^{*}$ Corresponding author.

How to cite this paper: Isoda, S., Kimura, T., Tanaka, K., Nishimura, K., Yamanaka, N., Taguchi, S., Uchida, K., Karube, N. and Imoto, K. (2015) Morbidity of Open Saphenous Vein Harvesting after Preoperative Ultrasonic Mapping. Open Journal of Thoracic Surgery, 5, 4-9. http://dx.doi.org/10.4236/ojts.2015.51002
} 


\section{Introduction}

The saphenous vein graft (SVG) is a commonly used conduit for coronary artery bypass surgery [1]. Saphenous vein harvesting for coronary bypass surgery is associated with significant morbidity. The morbidity associated with open harvesting is reportedly approximately $14 \%$ on average and ranges 3\% - 34\% [2] [3]. The morbidity associated with minimally invasive vein harvesting is reportedly approximately $3.5 \%$ on average and ranges $0 \%$ 8\% [2] [3]. Minimally invasive techniques for vein harvesting provide lower morbidity, compared to the open technique [4], although the use of minimally invasive techniques is limited to several institutes in our country because of the cost and the lack of manpower where physician assistants are unavailable.

In our institute, a saphenous vein graft is harvested by the open technique. We applied preoperative ultrasonic mapping to reduce making a useless incision to get an unqualified vein graft, to reduce unnecessary dissection of subcutaneous tissue, to obtain the shortest and most vertical approach to prevent causing poor blood flow in the subcutaneous tissue, and to know the availability of the proximal anastomosis device, which is not applicable for undersized or oversized veins (4 - $6 \mathrm{~mm}$ diameter). Previous study of saphenous vein harvest with ultrasonic mapping used ultrasonic study in the operating room [1]. The aim of this study was to assess the usefulness of preoperative ultrasonic saphenous vein mapping before surgery in conduit quality, conduit location, and reducing postoperative morbidity.

\section{Patients and Methods}

Between August 2008 and July 2010, 58 consecutive patients underwent coronary artery bypass grafting (CABG) at the National Defense Medical College. Preoperative saphenous vein graft (SVG) echography was performed in 31 elective patients; this procedure was not available for emergent or urgent patients because the echographer was not available in emergent or urgent situation. Otherwise there was no excusion criteria. Approval was obtained from the institutional review board of National Defense Medical College. Preoperative Doppler assessment revealed vein caliber, branching, and varicose saphenous veins. The saphenous vein location was marked. The caliber was measured at the saphenofemoral junction, femoral, knee, and ankle with the patient in the semiupright position. The ultrasound equipment used was the Toshiba Aplio color flow ultrasound system (Toshiba Medical Systems, Tochigi, Japan) with a PLT704AT linear array transducer (Toshiba Medical Systems) with 7.5 $\mathrm{MHz}$ frequency.

Saphenous veins were harvested with the open harvest technique via multiple (3 - 4) incisions on the line of the preoperative mapping. The vein caliber, length, and availability of proximal anastomosis devices were recorded. The wound was closed after protamine infusion and hemostasis by using running 3-0 braided absorbable sutures (Vicryl; Ethicone, Johnson \& Johnson Co-Ltd, Tokyo, Japan) to close the saphenous bed and subcutaneous layer, and by using horizontal running mattress sutures of 4-0 nonbraid absorbable sutures (PDS; Ethicone, Johnson \& Johnson) to close the epidermal layer. An elastic bandage was applied and was followed by elastic stocking.

Postoperative morbidity associated with saphenous vein harvesting was recorded. Morbidity included hematoma, skin detachment, infection, resuturing, skin necrosis, or any other cause for a delay in hospital discharge.

\section{Results}

Table 1 shows the patient demographics and surgical results. Most patients were treated with the off-pump procedure and two patients were converted to the on-pump procedure because of heart failure. There was no 30-day mortality. There was no saphenous vein harvesting morbidity associated with a delay in hospital discharge. Table 2 shows the details of preoperative saphenous vein mapping. Preoperative measurement of the saphenous vein caliber showed a rather large variability of $1.8-8.3 \mathrm{~mm}$. Four of 62 femoral saphenous veins and seven of 32 lower saphenous veins were "not graftable" because of varix, branches, or small size. There were side recommendations in seven of 31 patients. During harvesting, one of the 31 patients had wrong markings in which the saphenous vein was not located just beneath the marking. We were able to use all harvested veins.

Table 3 shows the actual caliber of the harvested saphenous veins. The difference between the preoperative ultrasonic estimated measurement and the actual measurement during surgery is also shown. Ultrasonic estimation showed a mean underestimation of $0.6 \mathrm{~mm}$. The variance of the difference was not small. We could use PAS-Port (Century Medical Inc., Tokyo, Japan) as the first choice of the anastomosis device in most patients. To use PAS-Port, the venous size must be 4 - $6 \mathrm{~mm}$ (Table 4). We needed to use other devices in two patients in 
whom the vein caliber was less than $4 \mathrm{~mm}$. For patients with saphenous vein preoperative ultrasonic estimation vein caliber under $3.4 \mathrm{~mm}$, the actual caliber was less than $4 \mathrm{~mm}$ in $20 \%$ of the patients and more than $4 \mathrm{~mm}$ in $80 \%$ of the patients.

Table 5 shows the incidence of morbidity associated with saphenous vein harvesting surgical site. There was morbidity with an incidence of $7.4 \%$ (Table 5). Skin necrosis was associated with a wrong marking. Hematoma was associated with excess warfarin effect in a patient who was under anticancer drug prescription.

Table 1. Patient demographics and surgical results.

$\begin{array}{cc}\text { CABG (SV mapped) } & 31 \text { patients (in 58 CABG) } \\ \text { Age, years (range) } & 70.4(59-83) \\ \text { On pump } & 2 \text { (conversion) } \\ \text { Distal anastomosis } & 3.0(1 \text { - 5) } \\ \text { ITA use } & 28 / 31 \text { patients } \\ \text { BITA use } & 6 / 31 \text { patients } \\ \text { SVG use } & 27 / 31 \text { patients } \\ \text { RA use } & 0 / 31 \text { patients } \\ \text { GEA use } & 0 / 31 \text { patients } \\ \text { ICU stay, days (range) } & 1.6(1-6) \\ \text { Hospital stay, days (range) } & 26.7(11-53) \\ \text { 30-day mortality } & 0 / 31 \text { patients } \\ \text { Deep sternal infection } & 0 / 31 \text { patients } \\ \text { ITA patency } & 29 / 29(100 \%) \\ \text { SVG patency (anastomosis) } & 45 / 51 \text { (88\%) }\end{array}$

BITA = bilateral internal thoracic artery; CABG = coronary artery bypass grafting; GEA = gastroepiploic artery; ICU = intensive care unit; ITA = internal thoracic artery; RA = radial artery; SV = saphenous vein; SVG = saphenous vein graft.

Table 2. Result of preoperative SV mapping $(\mathrm{n}=31)$.

\begin{tabular}{ccc}
\hline \multicolumn{2}{c}{ Cliber } & \multicolumn{1}{c}{ Lt } \\
\hline & \multicolumn{1}{c}{ Rt } & $5.3 \mathrm{~mm}(4.1-8.3)$ \\
\hline Femoral & $5.5 \mathrm{~mm}(2.9-7.8)$ & $3.8 \mathrm{~mm}(1.9-5.8)$ \\
Knee & $3.9 \mathrm{~mm}(1.9-6.3)$ & $3.8 \mathrm{~mm}(1.8-5.1)$ \\
Lower & $3.7 \mathrm{~mm}(1.9-4.8)$ & \\
Estimated as “Not Graftable” & \\
Femoral vein 4/62 (6.5\%) (varix, 2 veins; small, 2 veins) & \\
Lower vein 7/32 (21.8\%) (varix, 4 veins; branch, 2 veins; small, 1 vein) & \\
Side Recommendation in Femoral SV & \\
7/31 patients (22.6\%) (branch, 3 veins; small, 3 veins; varix, 2 veins)
\end{tabular}

$\mathrm{SV}=$ saphenous vein.

Table 3. Results of SV caliber $(n=31)$.

\begin{tabular}{ccc}
\hline SV harvested & $(n)$ & Actual caliber \\
\hline Rt femoral & $(13)$ & $4.4 \mathrm{~mm}(3.5-5)$ \\
Lt femoral & $(19)$ & $4.9 \mathrm{~mm}(4.25-5.75)$ \\
Rt lower leg & $(1)$ & $4.5 \mathrm{~mm}$ \\
Lt lower leg & $(1)$ & $4.5 \mathrm{~mm}$ \\
\hline Caliber Difference ( $\Delta$ actual - echo) Rt and Lt Femoral \\
\multicolumn{2}{c}{ actual } \\
\multicolumn{2}{c}{ echo } \\
\multicolumn{2}{c}{$\Delta$}
\end{tabular}

The data are expressed as the mean \pm the standard deviation. $\mathrm{Lt}=$ left; $\mathrm{Rt}=$ right; $\mathrm{SV}=$ saphenous vein. 
Table 4. Proximal anastomosis.

\begin{tabular}{|c|c|c|}
\hline Anastomosis device & & (Actual caliber, preop measurement) \\
\hline PAS-Port & 31 & (4 - $6 \mathrm{~mm}, 2.4-6.4 \mathrm{~mm})$ \\
\hline Enclose & 1 & (3.5 mm, $3.3 \mathrm{~mm})$ \\
\hline HEARTSTRING & 1 & (3.5 mm, $3.2 \mathrm{~mm})$ \\
\hline $\begin{array}{l}\text { Twilight caliber (echo } 2.4-3.3 n \\
\text { actual caliber }<4 \text { mm }(n=2) \\
\text { actual caliber }>4 \mathrm{~mm}(n=8)\end{array}$ & & \\
\hline
\end{tabular}

Table 5. Morbidity.

\begin{tabular}{cc}
\hline Morbidity in SV Mapping 2/27 (7.4\%) & \\
\hline Skin necrosis & 1 patient (wrong marking) \\
Hematoma & 1 patient (excess warfarin, anticancer drug use) \\
\hline Morbidity in Nonmapped SV Harvesting 3/26 (11.5\%) & 1 patient (damaged branch) \\
\hline SV damage & 2 patients \\
\hline Infection
\end{tabular}

$\mathrm{SV}=$ saphenous vein.

\section{Discussion}

The internal mammary artery and other arterial grafts have been used as conduits for coronary artery bypass grafting, although the saphenous vein remains an important conduit for coronary surgery. In our country, the saphenous vein is used in $81 \%$ of the patients who underwent coronary surgery during 2011 [5]. Therefore, there is unchanged importance to consider better harvesting maneuver of saphenous vein.

Standard open harvesting of the saphenous vein occasionally caused a certain incidence of morbidity, which included veins that were unavailable for harvesting because of branching; varicosity; surgical damage; small caliber; difficulty finding the vein because of technical problems, and an anomalous location; skin necrosis because of wide dissection used to find the saphenous vein, infection, burns, hematoma, nerve damage, neuralgia, and increased number of wounds because of unavailable vein harvesting. The morbidity associated with the open harvesting is reportedly approximately $14 \%$ on average, and ranges $3 \%-34 \%$ [2].

Endoscopic vein harvest was initiated to reduce the morbidity of the harvesting. Several reports pronounced a lower incidence of harvesting morbidity with endoscopic harvesting than with the standard open harvesting procedure [6]-[8]. The clinical benefit of endoscopic vein harvesting is well known, but it is not widely used in our country. The first reason is the difficulty in employing skilled manpower for harvesting in our country because physician assistants, who primarily perform harvesting in the United States, are unavailable in our country. Saphenous vein harvesting is a type of side job in a surgeon's duty in our country. The second reason is the cost because government insurance does not cover the cost of consumption supply for endoscopic harvesting in our country. Hospitals must pay for the endoscopic procedure, and standard open harvesting is cheaper. Some hospitals use endoscopic harvesting for harvesting wound complications only for high-risk patients (i.e., patients who have diabetes, obesity, and so on).

In our study, open harvesting with preoperative ultrasonic marking showed a low incidence of morbidity of $7.4 \%$, which is mostly similar to endoscopic harvesting. In the same period, we harvested 26 saphenous veins without preoperative ultrasonic marking and found morbidity in three (11.5\%) patients (Table 5). One branch was damaged during surgery, and two patients had wound infection at the harvesting site.

We should not compare the incidence between the mapped group and the nonmapped group because their backgrounds were different: the preoperatively mapped group had elective surgery, whereas the nonmapped group had urgent or emergent surgery. However, our impression is quite favorable for preoperative mapping. In the patients without preoperative mapping, we usually needed to perform a blunt dissection using a retractor to find the saphenous vein; however, with preoperative marking, we could simply cut the skin and subcutaneous tissue vertically to find the vein. Minimal dissection under the skin should provide proper blood supply for harvesting the surgical site. 
Preoperative ultrasonic mapping did provide valuable information concerning which side we should harvest. It also saved time that would have been consumed by unneeded harvesting whereby a rather long time is spent exploring the saphenous vein. A vein was occasionally not used for surgery because of the bad quality of the vein. In as many as $22.6 \%$ of the patients in our study, the side of the thigh to be harvested could be recommended, based on branching, varicose veins, and small vein size (Table 2). With this recommendation, we did not experience any chance of unavailable vein harvesting, and there was no wound in which the vein was not used for the bypass.

Proximal anastomosis devices have recently been introduced to reduce the operating time [9]. PAS-port (Century Medical Inc.) is a device that we now use as the first choice if the caliber of the veins is limited to 4.0 $6.0 \mathrm{~mm}$. Other anastomosis devices or a partial clamp for the ascending aorta need to be prepared if the vein is undersized or oversized. The mean caliber difference was $0.6 \mathrm{~mm}$, and the actual size was usually larger than the preoperative ultrasonic measurement. During preoperative sizing, saphenous veins with a diameter of $3.4 \mathrm{~mm}$ or larger were actually $4.0 \mathrm{~mm}$ or larger in diameter when measured in the operating room, and PAS-port (Century Medical Inc.) could be available. With $80 \%$ of preoperatively undersized veins (i.e., 2.4 - 3.3 mm in diameter), we could use PAS-port (Table 4). Preoperative mapping can provide information regarding the preparation of a proximal anastomosis device.

Limitation of this study is eventually small number of the patients. Saphenous vein harvesting using ultrasonic preoperative mapping with more patients will clear more detail of the clinical picture of saphenous vein mapping.

\section{Conclusion}

Preoperative ultrasonic measurement and marking provide an easy and sure way to find the saphenous vein, thereby resulting in a vertical incision, good healing of the wound, and diminished need for reharvesting. The morbidity of open saphenous vein harvesting with preoperative mapping does not differ much from the morbidity of endoscopic harvesting. The preoperative mapping procedure is therefore strongly recommended for open saphenous vein harvesting and may provide beneficial information concerning size, and branching, and may prevent useless harvesting, even for endoscopic harvesting.

\section{Conflicts of Interest}

Susumu Isoda and the other authors have no conflicts of interest to declare.

\section{Acknowledgements}

We thank Mr Yasuhito Hanba for data collection.

\section{References}

[1] Luckrutz, H., Lowe, J., Pugh, N. and Azzu, A.A. (2008) Pre-Operative Long Saphenous Vein Mapping Predicts Vein Anatomy and Quality Leading to Improved Post-Operative Leg Morbidity. Interactive CardioVasc Thoracic Surgery, 7, 188-191. http://dx.doi.org/10.1510/icvts.2007.166645

[2] Athanasiou, T., Aziz, O., Skapinakis, P., et al. (2003) Leg Wound Infection after Coronary Artery Bypass Grafting: A Meta-Analysis Comparing Minimally Invasive versus Conventional Vein Harvesting. The Annals of Thoracic Surgery, 76, 2141-2146. http://dx.doi.org/10.1016/S0003-4975(03)01435-8

[3] Puskas, J.D., Wright, C.E., Miller, P.K., et al. (1999) A Randomized Trial of Endoscopic versus Open Saphenous Vein Harvest in Coronary Bypass Surgery. The Annals of Thoracic Surgery, 68, 1509-1512. http://dx.doi.org/10.1016/S0003-4975(99)00952-2

[4] Aziz, O., Athanasiou, T. and Darzi, A. (2006) Minimally Invasive Conduit Harvesting: A Systematic Review. European Journal Cardio-Thoracic Surgery, 29, 324-333. http://dx.doi.org/10.1016/j.ejcts.2005.11.032

[5] Amano, J., Kuwano, H. and Yokomise, H. (2013) Thoracic and Cardiovascular Surgery in Japan during 2011. Annual Report by the Japan Association for Thoracic Surgery. General Thoracic and Cardiovascular Surgery, 61, 576-607. http://dx.doi.org/10.1007/s11748-013-0289-2

[6] Carpino, P.A., Khabbaz, K.R., Bojar, R.M., et al. (2000) Clinical Benefits of Endoscopic Vein Harvesting in Patients with Risk Factors for Saphenectomy Wound Infections Undergoing Coronary Artery Bypass Grafting. The Journal of Thoracic and Cardiovascular Surgery, 119, 69-75. http://dx.doi.org/10.1016/S0022-5223(00)70219-4 
[7] Dacey, L.J., Braxton Jr., J.H., Kramer, R.S., et al. (2011) Long-Term Outcomes of Endoscopic Vein Harvesting after Coronary Bypass Grafting. Circulation, 123, 147-153. http://dx.doi.org/10.1161/CIRCULATIONAHA.110.960765

[8] Ouzounian, M., Hassan, A., Buth, K.J., et al. (2010) Impact of Endoscopic versus Open Saphenous Vein Harvest Techniques on Outcomes after Coronary Artery Bypass Grafting. The Annals of Thoracic Surgery, 89, 403-408. http://dx.doi.org/10.1016/j.athoracsur.2009.09.061

[9] Kai, M., Hanyu, M., Soga, Y., Nomoto, T., Nakano, J., Matsuo, T., et al. (2009) Midterm Patency Rate after Saphenous Vein Grafting with a PAS-Port Device. The Journal of Thoracic and Cardiovascular Surgery, 137, 503-504. http://dx.doi.org/10.1016/j.jtcvs.2008.03.006 
Scientific Research Publishing (SCIRP) is one of the largest Open Access journal publishers. It is currently publishing more than 200 open access, online, peer-reviewed journals covering a wide range of academic disciplines. SCIRP serves the worldwide academic communities and contributes to the progress and application of science with its publication.

Other selected journals from SCIRP are listed as below. Submit your manuscript to us via either submit@scirp.org or Online Submission Portal.
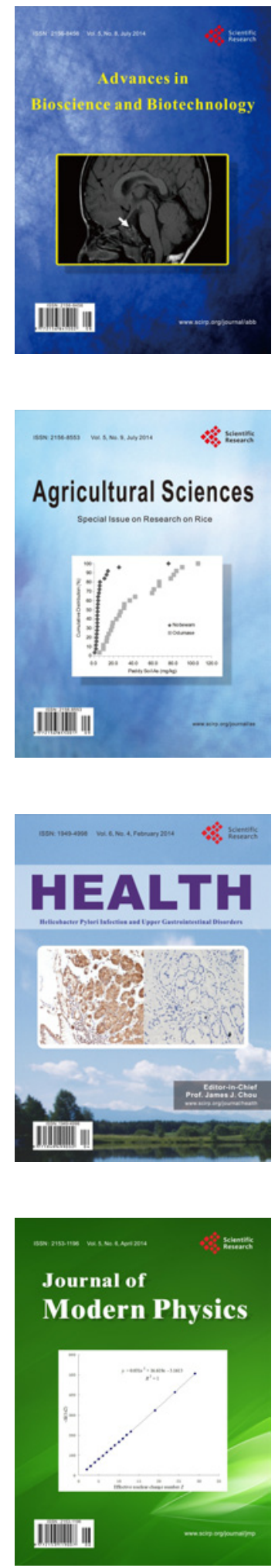
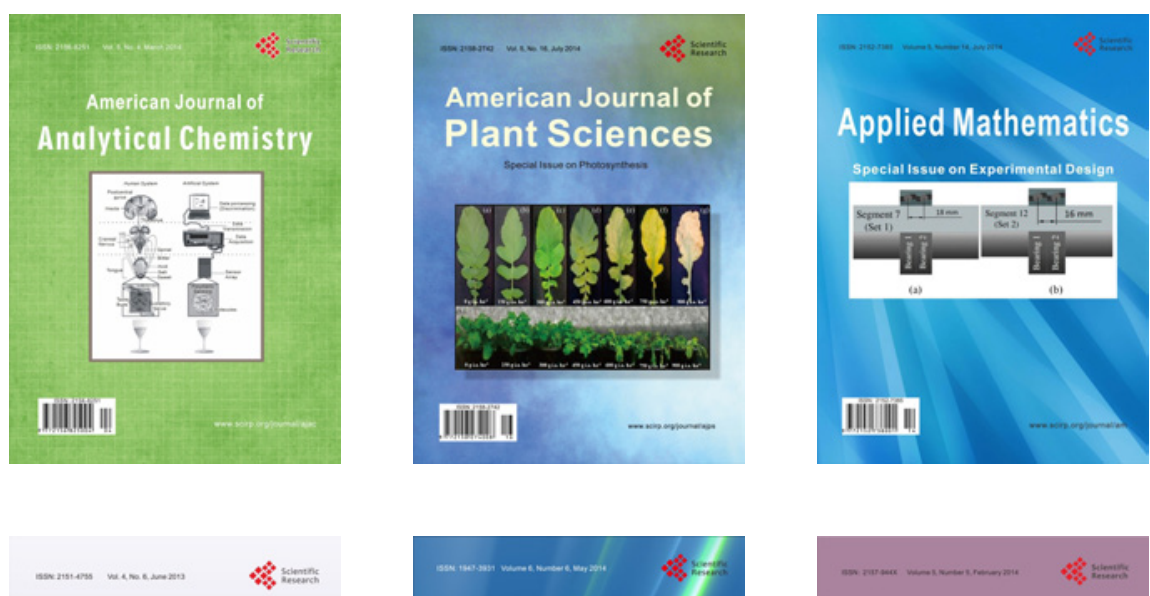

Creative Education
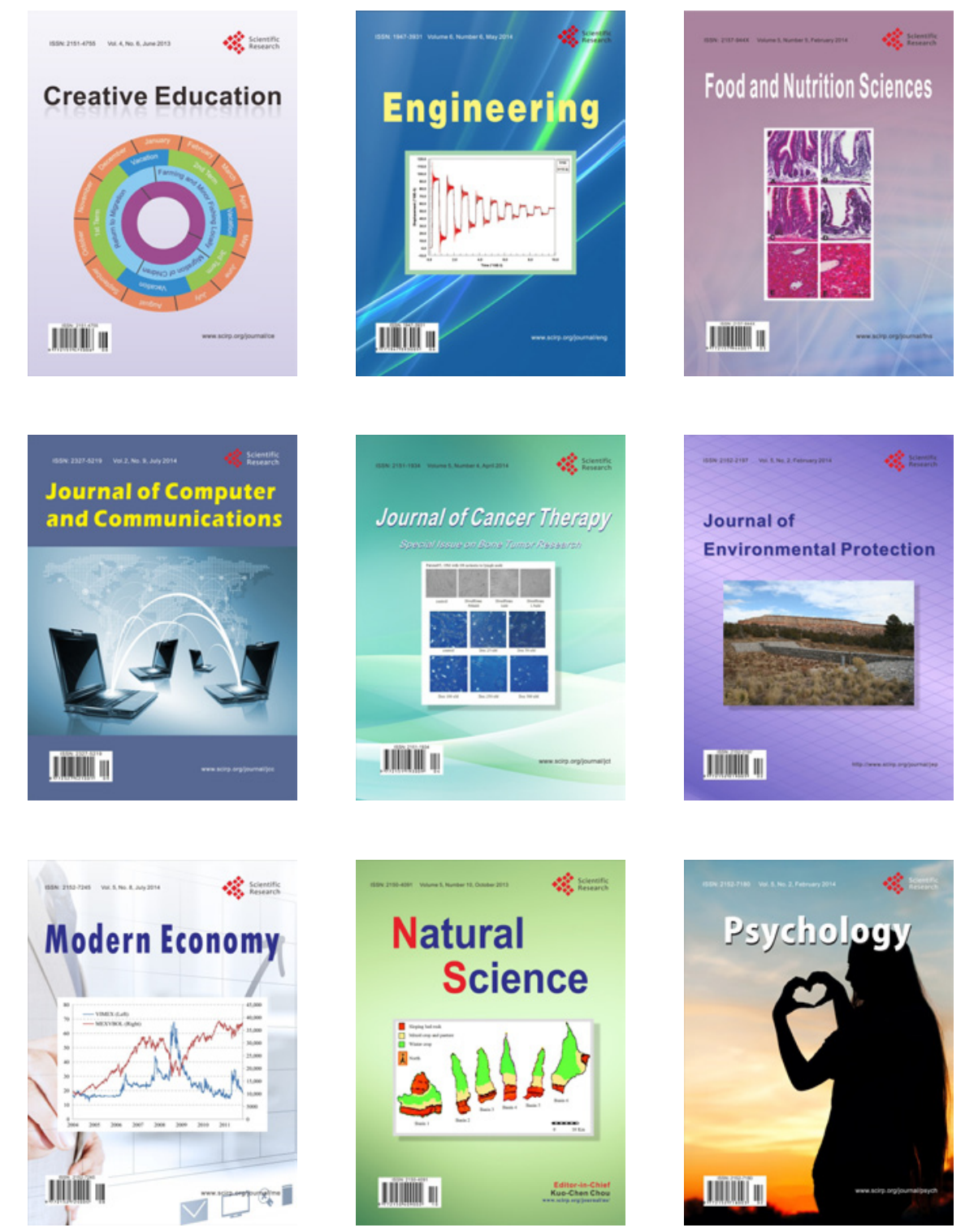